\title{
One pot synthesis of Biginelli 3,4-dihydro-1H-pyrimidin-2-ones and 1,2,3,4-tetrahydro pyrimidines
}

\author{
Md. E. Halim ${ }^{1 *}$, K. Akhter ${ }^{1}$, S. M. Ahmed ${ }^{2}$, Md. Al Amin Hossain ${ }^{1}$ and U. K. R. Romman ${ }^{1}$ \\ ${ }^{I}$ Department of Chemistry, University of Dhaka, Dhaka-1000, Bangladesh \\ ${ }^{2}$ Department of Chemistry, American International University-Bangladesh, 408/1 Kuratoli, Khilkhet, Dhaka-1229, Bangladesh
}

Received: 18 September 2019

Revised: 28 January 2020

Accepted: 08 July 2020

DOI: 10.3329/bjsir.v55i3.49390

\begin{abstract}
A simple and practical route for the Biginelli cyclocondensation reaction using anhydrous $\mathrm{ZnCl}_{2}$ as a catalyst in $\mathrm{n}$-heptane-toluene medium by reaction of substituted benzaldehydes, $1 \mathrm{a}-\mathrm{d}$ $\left(1 \mathrm{a}=2-\mathrm{ClC}_{6} \mathrm{H}_{4}-, 1 \mathrm{~b}=2-\mathrm{BrC}_{6} \mathrm{H}_{4}-\right.$ and $\left.1 \mathrm{c}=4-\mathrm{ClC}_{6} \mathrm{H}_{4}-1 \mathrm{~d}=2-\mathrm{H}_{3} \mathrm{CC}_{6} \mathrm{H}_{4}-\right)$ with 1, 3-dicarbonyl compounds, $2 \mathrm{a}-\mathrm{b}(2 \mathrm{a}=$ ethyl acetoacetate and $2 \mathrm{~b}=$ acetylacetone) and urea or thiourea, $3 \mathrm{a}-\mathrm{b}$ to give the corresponding Biginelli 3,4-dihydro- 1H-pyrimidin-2-ones and 1,2,3,4-tetrahydro pyrimidines, 4a-d. The structures of the compounds $4 \mathrm{a}-\mathrm{d}$ were confirmed by their ultraviolet, infrared, ${ }^{1} \mathrm{H} \mathrm{NMR},{ }^{13} \mathrm{C}$ NMR spectra and elemental analyses.
\end{abstract}

Keywords: Substituted benzaldehydes; Ethyl acetoacetate; Acetylacetone; Zinc chloride; Biginelli reaction

\section{Introduction}

The classical Biginelli condensation (Biginelli 1893) involving the reaction of an aldehyde, $\beta$-keto ester and urea or thiourea under strong acidic conditions to give 3,4-dihydropyrimidin-2(1H)-ones (DHPMs) which exhibit widespread biological applications. A large number of catalysts, solvent systems have been developed in accelerating this reaction since then. DHPMs are well known for their wide range of bioactivity and their application as calcium channel blockers, $\alpha$ 1-1-a-antagonists, antihypertensive agents, inhibitors of the fatty acid transporter and mitotic kinesin inhibition (Rovnyak et al., 1995; Van Zandt et al., 2005). These compounds have also been found to possess antiviral, antitumor, anti-inflammatory and antibacterial properties (Tsuruo et al., 1983; Kappe 1993, 2000). A huge number of reviews (Mirzaei et al., 2001; Shaaban et al., 2008; Cho et al., 1989; Rajeshwari et al., 2013) on synthesis and chemical properties of dihydropyrimidinones have already been published. Several marine alkaloids with interesting biological activities also contain the dihydropyrimidinone-5-carboxylate core (Snider et al., 1993). Most notably among these are the batzelladine alkaloids, which have been found to be potent HIV gp-120-CD4 inhibitors (Snider et al., 1996; Patil et al., 1995). The anti-cancer agent monastrol (Fig. 1) has been shown to specifically affect mitosis via a new mechanism consisting of the specific and reversible inhibition of the motility of the motor protein mitotic kinesin (Dondoni et al. 2002; Laville et al., 2009).

In order to improve the efficiency of Biginelli reaction coupled with the biological study of synthesized compounds many catalysts have been developed such as zirconium(IV) chloride (Reddy et al., 2002), indium(III) bromide (Fu et al., 2002), ceric ammonium nitrate (CAN) (Yadav et al., 2001), indium(III) chloride (Ranu et al., 2000), 


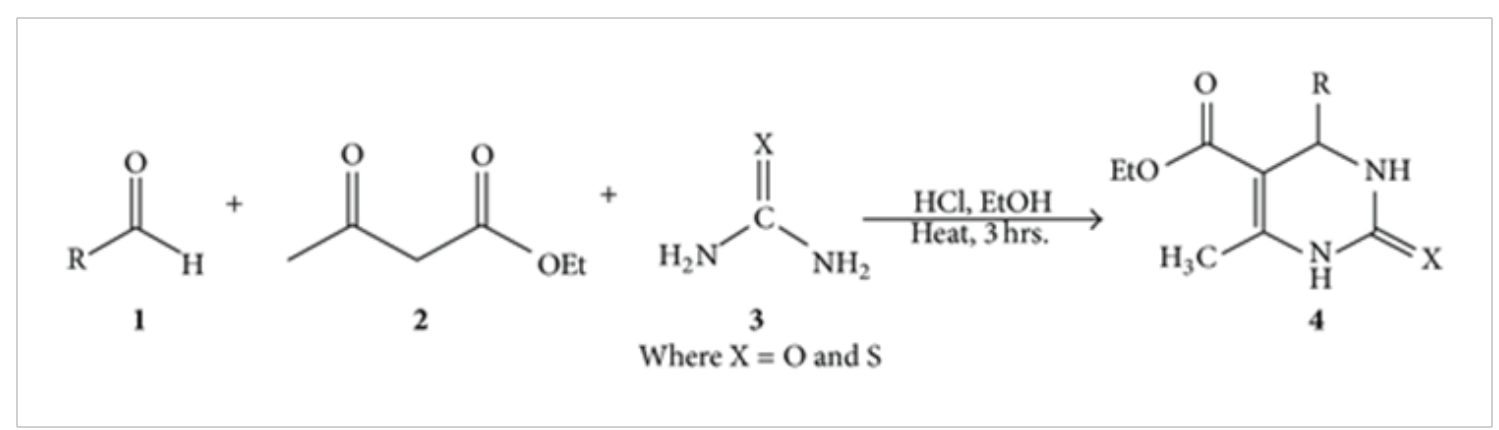

Scheme 1. Traditional Biginelli reaction

lanthanum chloride (Lu et al., 2000), Boric acid (Tu et al., 2003), lithium bromide (Maiti et al., 2003) silica/sulfuric acid (Salehi et al., 2003), vanadium(III) chloride (Sabitha et al., 2003), $\mathrm{FeCl}_{3} \cdot 6 \mathrm{H}_{2} \mathrm{O}$ (Lu et al., 2000), zinc triflate (Xu et al., 2003), trichloroacetic acid (Jaberi et al., 2012), nanosilica-supported tin(II) chloride (Ghomi et al., 2013), Bronsted acid (Anjaneyulu et al., 2015), L-proline nitrate (Bahekar et al., 2017), $\operatorname{InBr}_{3}$ (Maskrey et al., 2018) and $\mathrm{Hf}(\mathrm{OTf})_{4}$ (Kong et al., 2019). Some of these catalysts are really very fascinating from a synthetic chemist's point. Despite their tremendous success, however, some drawbacks still remain. For example, some of the catalysts are expensive, complex or unavailable.

In the past 20 years, several one-pot methodologies for the synthesis of DHPM derivatives were developed and several modifications have been introduced. Most of them are based on Lewis acid-catalyzed reactions (Paraskar et al., 2003; Sabitha et al., 2005; Azizian et al., 2006; Sadek et al., 2010; Shapiro and Vigalok, 2008; Salim and Akamanchi, 2011; Chitra and Pandiarajan, 2009; Mandhane et al., 2010) which permits the reaction to proceed under milder conditions and with higher yields, than those out-lined by Biginelli in the original procedure. Microwave irradiation has also proved beneficial (Pasunooti et al., 2011). Natural acidic catalysts have been also utilized (Patil et al., 2011).

Biginelli reaction has also been conducted under basic conditions. This involves the use of $\mathrm{PPh}_{3}$, under solvent free conditions (Debache et al., 2008), $t$-BuOK at $70^{\circ} \mathrm{C}$ (Shen et al., 2010), chiral primary amines (Ding and Zhao, 2010) and ammonium carbonate in water (Tamaddon et al., 2010). It is worth mentioning that many of these existing methods displayed drawbacks, such as environmental pollution caused by utilizing catalysts in stoichiometric quantities, exotic reaction conditions, unsatisfactory yields and complicated operations while others possess some advantages overcoming these drawbacks. Zinc chloride, a very inexpensive and easily available Lewis acid catalyst, has been widely used in organic reactions, but it hasn't been carefully studied as a catalyst in Biginelli condensation until now, except for a few mentions in literature (Sun et al., 2004).<smiles>CCOC(=O)C1=C(C)NC(=S)NC1c1cccc(O)c1</smiles>

Fig. 1. Monostrol

In continuation of our interest in the synthesis of fused pyrimidines (Akhter et al., 2015), we report herein a simple and practical route for the Biginelli cyclocondensation reaction using $\mathrm{ZnCl}_{2}$ as a catalyst in n-heptane-toluene medium. This is a novel, one pot combination that not only preserves the simplicity of Biginelli's one pot reaction but also consistently produce excellent yields of the di (or tetra) hydropyrimidinones, $4 \mathrm{a}-\mathrm{d}$ (Scheme 2 ). The compounds $4 \mathrm{a}-\mathrm{d}$ do not seem to be available in the literature.

\section{Materials and methods}

All chemicals were purchased from E. Merck. Thin layer chromatography (TLC) was carried out on plates percolated with silica gel 60 F254 and spots were detected with iodine vapour. Melting points were determined on an Electro thermal micro melting-point apparatus and uncorrected. The Ultraviolet spectra of the samples were recorded on a Shimadzu UV-160A spectrometer with a scanning range of 800-200 nm using methanol as solvent. IR spectra were recorded with Shimadzu IR 470A spectrophotometer in the range $4000-400 \mathrm{~cm}^{-1}$. The ${ }^{1} \mathrm{H}$ NMR and ${ }^{13} \mathrm{C}$ NMR spectra of 


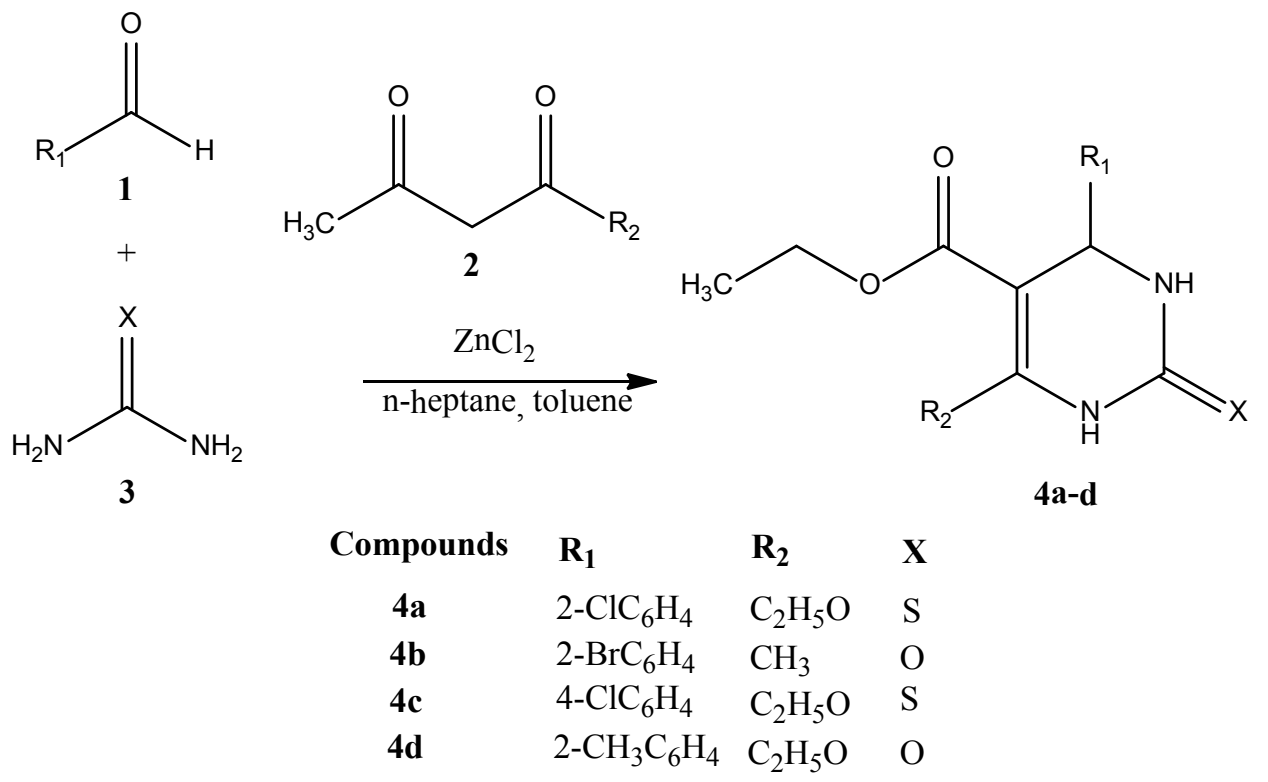

Scheme 2. Synthesis of the compounds, 4a-d

the samples were recorded on a Bruker $400 \mathrm{MHz}$ spectrophotometer using DMSO- $\mathrm{d}_{6}$ as solvent with Tetramethylsilane (TMS) as an internal standard.

\section{General procedure}

A mixture of a benzaldehyde (10 mmol), a 1,3-dicarbonyl compound $(10 \mathrm{mmol})$, urea or thiourea $(15 \mathrm{mmol})$ and $\mathrm{ZnCl}_{2}$ $(273 \mathrm{mg}, 2 \mathrm{mmol})$ was refluxed in heptane-toluene $(30 \mathrm{~mL}$, 1:1) medium under magnetic stirring for 4 hours. Upon completion of the reaction, as indicated by TLC, the reaction mixture was cooled to room temperature, poured onto $30 \mathrm{ml}$ of water. The resulting solid was filtered under suction and successively washed with $\mathrm{H}_{2} \mathrm{O}(30 \mathrm{ml})$ and petroleum etherEtOAc $(5: 1,30 \mathrm{ml})$. The crude product was then purified by re-crystallization (acetone-ethanol mixture) to give pure product. Compounds obtained according to this procedure were characterized and identified by their melting points, UV, FT-IR, ${ }^{1} \mathrm{H}-\mathrm{NMR},{ }^{13} \mathrm{C}-\mathrm{NMR}$ and elemental analyses.

4-(2-Chlorophenyl)-6-methyl-2-thioxo-1,2,3,4-tetrahydro-py rimidine-5-carboxylic acid ethyl ester, 4a:

Yield 78\%; white crystalline solid; $\mathrm{mp} 164-165^{\circ} \mathrm{C} ; \mathrm{R}_{\mathrm{f}}$ value in TLC 0.85 (Ethyl acetate: Chloroform,1:4); UV ( $\lambda_{\max }$ in $\left.n m\right)$ : $305\left(\pi \rightarrow \pi^{*} / \mathrm{n} \rightarrow \pi^{*}\right.$ of $\left.\mathrm{C}=\mathrm{O}\right)$; IR $(\mathrm{KBr})\left(v_{\max } \mathrm{cm}^{-1}\right): 3180(\mathrm{~N}-\mathrm{H}$ stretching), $1708(\mathrm{C}=\mathrm{O}), 1654(\mathrm{C}=\mathrm{C}$ in conj. with $\mathrm{C}=\mathrm{O})$,
$1444\left(\mathrm{C}=\mathrm{S}\right.$ stretching), 1089 (Aromatic-Cl); ${ }^{1} \mathrm{H}$ NMR $\delta$ (in ppm): 8.81 (s, 1H, N-H, 1-H), 7.67 (s, 1H, N-H, 3-H), 7.36 (d, $\left.1 \mathrm{H}, \mathrm{J}=7.8 \mathrm{~Hz}, 3^{\prime}-\mathrm{H}\right), 7.24-7.20$ (m, 3H, 4', 5' \& 6'-H), 5.89 (d, 1H, J=3.0 Hz, 4-H), 4.01 (q, 2H, J=7.2, $\mathrm{CH}_{3} \mathrm{CH}_{2} \mathrm{COO}-$ ), $2.43\left(\mathrm{~s}, \quad 3 \mathrm{H}, \quad \mathrm{CH}_{3}-\mathrm{C}_{6}=\mathrm{C}_{5}-\right), 1.05 \quad(\mathrm{t}, 3 \mathrm{H}, \quad \mathrm{J}=4.8 \mathrm{~Hz}$, $\mathrm{CH}_{3} \mathrm{CH}_{2} \mathrm{COO}-$ ); ${ }^{13} \mathrm{C}$ NMR $\delta$ (in ppm): 174.02 (C-2), 164.82 $\left(\mathrm{CH}_{3} \mathrm{CH}_{2}\right.$ COO-), 144.62 (C-6), 138.50 (1'), 132.51(2'), $129.78\left(3^{\prime}\right), \quad 129.57\left(6^{\prime}\right), \quad 128.51\left(4^{\prime}\right), \quad 127.60\left(5^{\prime}\right)$ (6C-aromatic), 100.73 (5-C), 60.26 ( $\left.\mathrm{CH}_{3} \mathrm{CH}_{2} \mathrm{COO}-\right), 52.56$

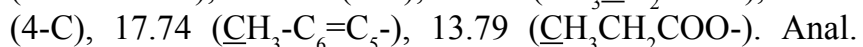
Found: C, 54.20; H, 4.90; N, 8.98; Calc. for $\mathrm{C}_{14} \mathrm{H}_{15} \mathrm{ClN}_{2} \mathrm{O}_{2} \mathrm{~S}$ : C, 54.10; H, 4.86; N, 9.01\%.

5-Acetyl-4-(2-bromophenyl)-6-methyl-3,4-dihydro-1H-pyri midin-2-one, $4 b$ :

Yield 70\%; Off white crystalline solid; mp 224-226 ${ }^{\circ} \mathrm{C} ; \mathrm{R}_{\mathrm{f}}$ value in TLC 0.44 (Neat Chloroform); $\operatorname{UV}\left(\lambda_{\max }\right.$ in $\left.\mathrm{nm}\right): 301$ $\left(\pi \rightarrow \pi^{*} / \mathrm{n} \rightarrow \pi^{*}\right.$ of $\left.\mathrm{C}=\mathrm{O}\right)$; IR $(\mathrm{KBr})\left(v_{\max } \mathrm{cm}^{-1}\right): 3252(\mathrm{~N}-\mathrm{H}$ stretching), $1705(\mathrm{C}=\mathrm{O}), 1624(\mathrm{C}=\mathrm{C}$ in conj. with $\mathrm{C}=\mathrm{O})$, 1026 (Aromatic-Br); ${ }^{1} \mathrm{H}$ NMR $\delta$ (in ppm): 9.27 (s, 1H, N-H, 1-H), 7.67 (s, 1H, N-H, 3-H), 7.59 (d, 1H, J=8.4 Hz, 3'-H), 7.35 (d, 1H, J=7.8 Hz, 5'-H), 7.25 (d, 1H, J=7.2 Hz, 6'-H), 7.19 (d, 1H, J=7.8 Hz, 4'-H), $5.61(\mathrm{~d}, 1 \mathrm{H}, \mathrm{J}=3.0 \mathrm{~Hz}$,

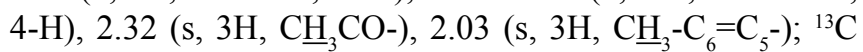
NMR $\delta$ (in ppm): 201.26 ( $\left.\mathrm{CH}_{3} \mathrm{CO}-\right), 160.83$ (C-2), 139.56 (C-6), 145.22 (1'), 122.80 (2'), 130.56 (3’), 129.46 (6’), 
$128.17\left(4^{\prime}\right), 127.44$ (5') (6C-aromatic), 105.41 (5-C), 51.92 (4-C), 26.22 ( $\left.\mathrm{CH}_{3} \mathrm{CO}-\right), 17.82\left(\underline{\mathrm{CH}}_{3}-\mathrm{C}_{6}=\mathrm{C}_{5}-\right)$. Anal. Found: $\mathrm{C}$, 50.60; H, 4.32; N, 8.99; Calc. for $\mathrm{C}_{13} \mathrm{H}_{13} \mathrm{BrN}_{2} \mathrm{O}_{2}$ : C, 50.50; H, $4.24 ; \mathrm{N}, 9.06 \%$.

4-(4-Chlorophenyl)-6-methyl-2-thioxo-1,2,3,4-tetrahydro-py rimidine-5-carboxylic acid ethyl ester, $4 c$ :

Yield 38\%; yellowish crystalline solid; mp $168-170^{\circ} \mathrm{C} ; \mathrm{R}_{\mathrm{f}}$ value in TLC 0.52 (Neat ethyl acetate); $\mathrm{UV}\left(\lambda_{\max }\right.$ in $\left.\mathrm{nm}\right): 285$ $\left(\pi \rightarrow \pi^{*} / \mathrm{n} \rightarrow \pi^{*}\right.$ of $\left.\mathrm{C}=\mathrm{O}\right)$; IR $(\mathrm{KBr})\left(v_{\max } \mathrm{cm}^{-1}\right): 3276(\mathrm{~N}-\mathrm{H}$ stretching), $1750(\mathrm{C}=\mathrm{O}), 1612(\mathrm{C}=\mathrm{C}$ in conj. with $\mathrm{C}=\mathrm{O})$, $1415\left(\mathrm{C}=\mathrm{S}\right.$ stretching), 1084 (Aromatic-Cl); ${ }^{1} \mathrm{H}$ NMR $\delta$ (in ppm): 7.44 (s, 1H, N-H, 1-H), 7.41 (s, 1H, N-H, 3-H), 7.29 (d, $2 \mathrm{H}, \mathrm{J}=7.8 \mathrm{~Hz}, 3$ '\& 5'-H), 7.22 (d, 2H, J=8.4 Hz, 2' \& 6'-H), $5.36(\mathrm{~d}, 1 \mathrm{H}, \mathrm{J}=2.49 \mathrm{~Hz}, 4-\mathrm{H}), 4.08 \quad(\mathrm{q}, 2 \mathrm{H}, \mathrm{J}=6.6$, $\left.\mathrm{CH}_{3} \mathrm{CH}_{2} \mathrm{COO}-\right), 2.34$ (s, 3H, $\left.\mathrm{CH}_{3}-\mathrm{C}_{6}=\mathrm{C}_{5}-\right), 1.17$ (t, 3H, J=7.2 $\mathrm{Hz}, \mathrm{CH}_{3} \mathrm{CH}_{2} \mathrm{COO}-$ ); ${ }^{13} \mathrm{C}$ NMR $\delta$ (in ppm): 173.89 (C-2), 165.02 ( $\left.\mathrm{CH}_{3} \mathrm{CH}_{2} \mathrm{COO}-\right), \quad 145.22 \quad$ (C-6), 139.50 (1'), 128.52(2'), 129.88(3'), 128.58(6'), 130.51(4'), 129.90(5') (6C-aromatic), 101.61 (5-C), 59.96 ( $\left.\mathrm{CH}_{3} \mathrm{CH}_{2} \mathrm{COO}-\right), 52.12$ (4-C), $17.77\left(\underline{\mathrm{CH}}_{3}-\mathrm{C}_{6}=\mathrm{C}_{5}-\right), 13.72\left(\underline{\mathrm{CH}}_{3} \mathrm{CH}_{2} \mathrm{COO}-\right)$. Anal. Found: C, 54.22; H, 4.82; N, 8.98; Calc. for $\mathrm{C}_{14} \mathrm{H}_{15} \mathrm{ClN}_{2} \mathrm{O}_{2} \mathrm{~S}$ : C, 54.10; H, 4.86; N, 9.01\%.

6-Methyl-2-oxo-4-o-tolyl-1,2,3,4-tetrahydro-pyrimidine-5-c arboxylic acid ethyl ester, $4 d$ :

Yield 70\%; white crystalline solid; mp 207-208 ${ }^{\circ} \mathrm{C} ; \mathrm{R}_{\mathrm{f}}$ value in TLC 0.72 (Ethyl acetate: Chloroform, 1:1); UV $\left(\lambda_{\max }\right.$ in $\left.\mathrm{nm}\right): 292\left(\pi \rightarrow \pi^{*} / \mathrm{n} \rightarrow \pi^{*}\right.$ of $\left.\mathrm{C}=\mathrm{O}\right)$; IR $(\mathrm{KBr})$ (v $\left.{ }_{\max } \mathrm{cm}^{-1}\right): 3235(\mathrm{~N}-\mathrm{H}$ stretching $), 1700(\mathrm{C}=\mathrm{O}), 1643(\mathrm{C}=\mathrm{C}$ in conj. with $\mathrm{C}=\mathrm{O}) ;{ }^{1} \mathrm{H}$ NMR $\delta$ (in ppm): $8.43(\mathrm{~s}, 1 \mathrm{H}, \mathrm{N}-\mathrm{H}$, 1-H), 5.81 (s, 1H, N-H, 3-H), 7.24-7.20 (m, 4H, 3', 4', 5' \& $\left.6^{\prime}-\mathrm{H}\right), 5.64$ (bs, 1H, 4-H), 3.97 (q, 2H, J=7.2, $\left.\mathrm{CH}_{3} \mathrm{CH}_{2} \mathrm{COO}-\right), 2.41$ (s, 3H, $\left.\mathrm{Ar}-\mathrm{CH}_{3}\right), 2.35(\mathrm{~s}, 3 \mathrm{H}$, $\left.\mathrm{C}_{3}-\mathrm{C}_{6}=\mathrm{C}_{5}-\right), 1.05\left(\mathrm{t}, 3 \mathrm{H}, \mathrm{J}=7.2 \mathrm{~Hz}, \mathrm{CH}_{3} \mathrm{CH}_{2} \mathrm{COO}-\right) ;{ }^{13} \mathrm{C}$ NMR $\delta$ (in ppm): 153.13 (C-2), 165.64 ( $\mathrm{CH}_{3} \mathrm{CH}_{2}$ COO-), 141.40 (C-6), 146.82 (1'), 132.59 (2'), 130.66 (3'), 127.86 (6’), 127.17 (4'), 126.84 (5') (6C-aromatic), 100.64 (5-C), 59.89 ( $\left.\mathrm{CH}_{3} \underline{\mathrm{CH}}_{2} \mathrm{COO}-\right), 52.18$ (4-C), 18.92 $\left(\underline{\mathrm{CH}}_{3}-\mathrm{C}_{6}=\mathrm{C}_{5}{ }^{-}\right), 18.45\left(\mathrm{Ar}-\underline{\mathrm{CH}}_{3}\right), 14.04\left(\underline{\mathrm{CH}}_{3} \mathrm{CH}_{2} \mathrm{COO}-\right)$. Anal. Found: $\mathrm{C}, 65.61 ; \mathrm{H}, 6.70 ; \mathrm{N}, 10.11$; Calc. for $\mathrm{C}_{15} \mathrm{H}_{18} \mathrm{~N}_{2} \mathrm{O}_{3}$ : C, 65.68; H, 6.61; N, 10.21\%.

\section{Results and discussion}

The one-pot synthesis of di (or tetra) hydropyrimidines $4 \mathrm{a}-\mathrm{d}$ were synthesized by the three component condensation of substituted benzaldehydes 1a-d, with corresponding $\beta$-dicarbonyl compounds $2 \mathrm{a}-\mathrm{b}$ and urea or thiourea $3 \mathrm{a}-\mathrm{b}$ in presence of anhydrous zinc chloride in heptane-toluene under refluxing conditions in an analogous manner reported previously (Akhter et al., 2015). The structures of the compounds $4 \mathrm{a}-\mathrm{d}$ were confirmed based on their UV, FT-IR, ${ }^{1} \mathrm{H}$ NMR, ${ }^{13} \mathrm{C}$ NMR and elemental analyses.

The compounds $4 \mathrm{a}$ - $\mathrm{d}$ agree well to the expected $\lambda_{\max }$ values in their UV spectra. The absorption bands in the range 305-285 $\mathrm{nm}$ may be assigned to the $\pi \rightarrow \pi^{*}$ of $\mathrm{C}=\mathrm{O}$ in these compounds. The weak $n \rightarrow \pi^{*}$ absorption bands in the cases of these compounds due to $\mathrm{C}=\mathrm{O}$ were probably masked within the $\pi \rightarrow \pi^{*}$ absorption range.

The IR data of the compounds 4a-d showed sharp as well as broad bands in the range $\left(v_{\max }\right) 3276-3180 \mathrm{~cm}^{-1}$ indicating the presence of N-H group. The absorption bands at 1750-1700 $\mathrm{cm}^{-1}$ indicate the presence of non-conjugated $\mathrm{C}=\mathrm{O}$ stretching including the pyrimidine moieties. The bands at 1654-1612 $\mathrm{cm}^{-1}$ were assigned to $\mathrm{C}=\mathrm{C}$ of aromatic rings in conjugation with $\mathrm{C}=\mathrm{O}$ and $1444-1415 \mathrm{~cm}^{-1}$ for $\mathrm{C}-\mathrm{S}$ stretching of compounds $4 \mathrm{a}$ and $4 \mathrm{c}$. Additional bands were observed at 1089-1026 cm- ${ }^{-1}$ due to presence of halogenated aromatics of compounds $4 \mathrm{a}, 4 \mathrm{~b}$ and $4 \mathrm{c}$.

In their ${ }^{1} \mathrm{H}$ NMR spectra of compounds $4 \mathrm{a}-\mathrm{d}$, the $\mathrm{N}-\mathrm{H}$ protons were relatively deshielded $(\delta$ 9.27-7.44) and appeared as singlet due to anisotropy and presence of electronegative atoms attached to this group. The proton at position 4 appeared as a doublet (or broad singlet) gave signals at $\delta$ 5.89-5.36 due to the vicinal coupling with the proton at position 3 . The methylene protons ( $4 \mathrm{a}, 4 \mathrm{c}$ and $4 \mathrm{~d}$ ) appeared as quartet being attached to a methyl in one side and an ester on the other side further deshielded due to direct link with one oxygen of ester group and gave peaks at $\delta 4.08-3.97 \mathrm{ppm}$. The methyl protons in these compounds attached to an alkene carbons gave peaks at $\delta 2.43-2.03 \mathrm{ppm}$ and another methyl protons (4b) attached to carbonyl group gave peaks at $\delta 2.32$ ppm as singlet. The aromatic methyl of compound $4 \mathrm{~d}$ appeared as singlet and gave signal at $\delta 2.41 \mathrm{ppm}$. The methyl protons of ester group ( $4 \mathrm{a}, 4 \mathrm{c}$ and $4 \mathrm{~d})$ appeared as triplets and gave signals at $\delta 1.17-1.04 \mathrm{ppm}$. All aromatic protons have shown peaks in their expected positions.

The structures of the compounds $4 \mathrm{a}-\mathrm{d}$ were further confirmed by their ${ }^{13} \mathrm{C}$ NMR spectra. The chemical shifts of carbonyl carbon at 2-C were found to be deshielded in the range of $\delta$ 174.02-153.13. The chemical shifts of $\mathrm{CH}_{3} \mathrm{CO}$ - of compound $4 \mathrm{~b}$ was further deshielded ( $\delta$ 201.26). The chemical shift values for $-\mathrm{COOCH}_{2} \mathrm{CH}_{3}$ in compounds $4 \mathrm{a}$, 4c and $4 \mathrm{~d}$ were observed at ( $\delta$ 165.64-164.82). The chemical shifts of 6-C were similarly deshielded ( $\delta$ 145.22-139.56). The 5-C of the compounds showed chemical shift values at $\delta$ 105.40-100.64. The chemical shift values for 4-C in these compounds were 
observed at $\delta$ 52.56-51.92. The chemical shift values for methyl carbon attached to alkene $\left(\mathrm{C}_{6}=\mathrm{C}_{5}\right)$ in these compounds were observed at $\delta$ 18.92-17.74. The chemical shift values for $-\mathrm{COOCH}_{2} \mathrm{CH}_{3}$ and $-\mathrm{COOCH}_{2} \underline{\mathrm{CH}}_{3}$ in compounds $4 \mathrm{a}, 4 \mathrm{c}$ and $4 \mathrm{~d}$ were observed at $\delta 60.26-59.89$ and 14.04-13.71 respectively. The chemical shift values for $\mathrm{CH}_{3} \mathrm{CO}$ - in compound $4 \mathrm{~b}$ and aromatic methyl carbon in compound $4 \mathrm{c}$ were observed at $\delta 26.22$ and 18.45 respectively. The ${ }^{13} \mathrm{C}$ NMR chemical shifts for the carbons of aromatic rings were found in their expected positions.

Although different mechanistic pathways have been proposed previously (Tamaddon et al 2010), we believe that the reaction may proceed through an initially formed imine intermediate [I] from the reaction of the aldehyde, 1 and urea or thiourea, 3 (Scheme-3). The co-ordination of the lone pair of the nitrogen atom with the Lewis acid could lead to the in situ formation of iminum ion [II] which is sufficient electrophile to react with the enol form of ethyl acetoacetate, 2 affording finally intramolecular cyclization with loss of $\mathrm{H}_{2} \mathrm{O}$ molecule, producing di (or tetra) hydropyrimidines, $4 \mathrm{a}-\mathrm{d}$.

\section{Acknowledgement}

The authors are grateful to Professor Teruo Shinmyozu, Department of Molecular Chemistry, Institute of Materials Chemistry \& Engineering (IMCE), Kyushu University, Fukuoka, Japan for his kind cooperation and giving the support for elemental analyses of the synthesized compounds.

\section{References}

Akhter K, Jahan K, Romman UKR, Ahmed MG, Rahman MS and Amin MA (2015), A green approach to synthesize dihydropyrimidinone derivatives by using anhydrous $\mathrm{ZnCl}_{2}$ catalyst under refluxing condition in heptane-toluene medium via Biginelli Reaction, Asian J. Chem. 27: 2624-2626.

Anjaneyulu B and Dharma Rao GB (2015), A mini review: Biginelli reaction for the synthesis of dihydropyrimidinones, Int. J. Eng. Tech. Res. 3(6): 26-37.

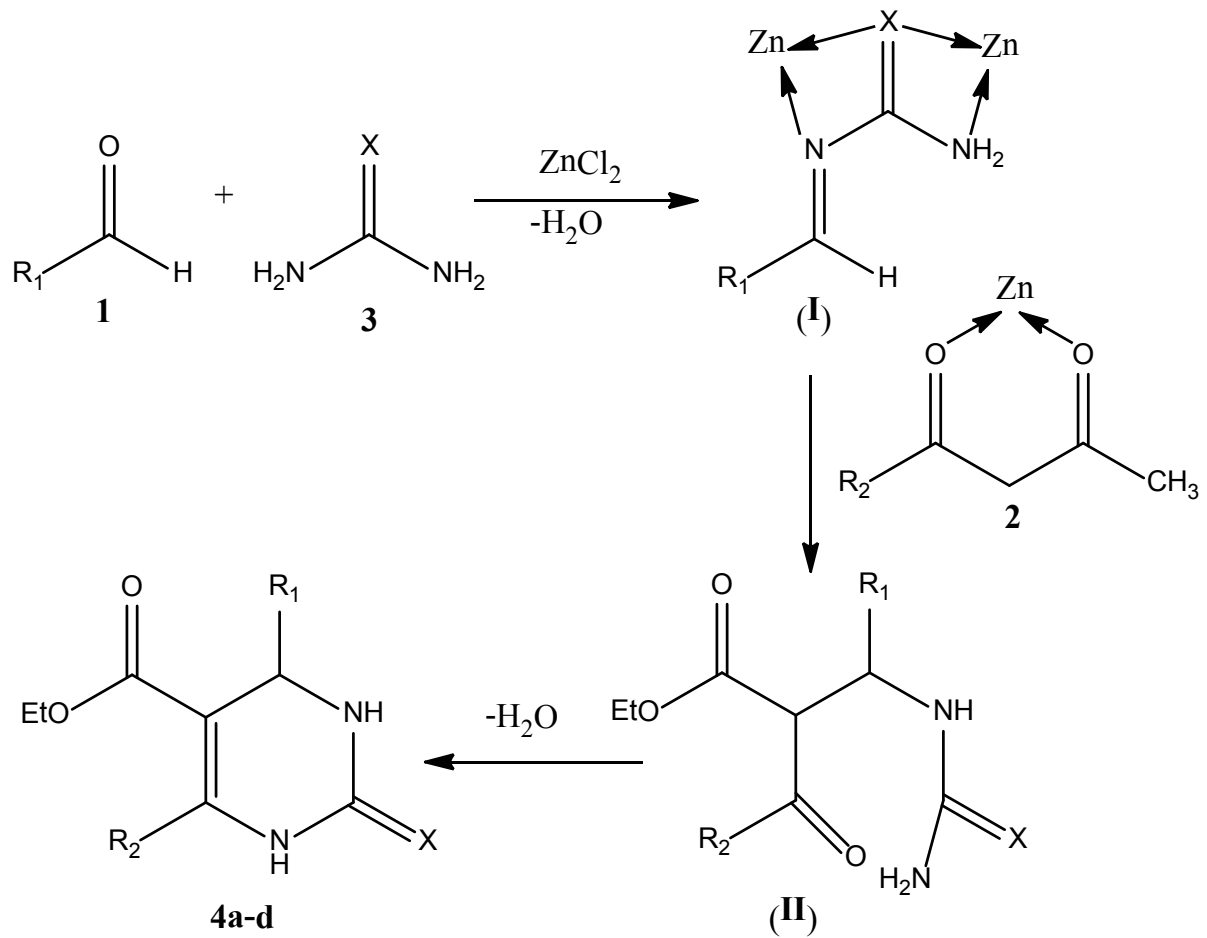

Where $\mathrm{R}_{1}=$ Subs. phenyl, $\mathrm{R}_{2}=-\mathrm{CH}_{3}$ or $-\mathrm{OCH}_{2} \mathrm{CH}_{3}$ and $\mathrm{X}=\mathrm{O}$ or $\mathrm{S}$

Scheme 3. A plausible reaction mechanism for 4 a-d 
Azizian J, Mohammadi AA, Karimi AR and Mohammadizadeh MR (2006), $\mathrm{KAl}\left(\mathrm{SO}_{4}\right) \cdot 12 \mathrm{H}_{2} \mathrm{O}$ supported on silica gel as a novel heterogeneous system catalyzed Biginelli reaction: one-pot synthesis of dihydropyrimidinones under solvent-free conditions, Appl. Catal. A: General 300: 85-88.

Bahekar SP, Sarode PB, Wadekar MP, and Chandak HS (2017), Simple and efficient synthesis of 3,4-dihydropyrimidin-2(1H)-thiones utilizing L-proline nitrate as a proficient, recyclable and eco-friendly catalyst, J. Saudi Chem. Soc. 21: 415-419. DOI: org/10.1016/j.jscs.2015.09.004

Biginelli P (1893), Derivati aldeiduredici degli eteri acetile dossal-acetico, Gazzetta Chimica Italiana 23: 360-416.

Chitra S and Pandiarajan K (2009), Calcium fluoride: an efficient and reusable catalyst for the synthesis of 3 , 4-dihydropyrimidin-2(1H)-ones and their corresponding 2-(1H)-thiones: an improved high yielding protocol for Biginelli reaction, Tetrahedron Lett. 50: 2222-2224.

Cho H, Ueda M, Shima K, Mizuno A, Hayashimatsu M, Ohnaka Y, Takeuchi Y, Hamaguchi M and Aisaka K (1989), Dihydropyrimidines: Novel calcium antagonists with potent and long-lasting vasodilative and anti-hypertensive activity, J. Med. Chem. 32: 2399-2406.

Debache A, Amimour M, Belfaitah A, Rhouati S and Carboni B (2008), A one-pot Biginelli synthesis of 3, 4-dihydropyrimidin-2(1H)-ones/thiones catalyzed by triphenyl phosphine as Lewis base," Tetrahedron Lett. 49: 6119-6121. DOI: org/10.1016/ j.tetlet.2008.08.016

Ding D and Zhao CG (2010), Primary amine catalyzed Biginelli reaction for the enantioselective synthesis of 3,4-dihydropyrimidin-2(1H)-ones, Eur. J. Org. Chem. 2010: 3802-3805.

Dondoni A, Massi A and Sabbatini S (2002), Improved synthesis and preparative scale resolution for racemic monastrol, Tetrahedron Lett. 43: 5913-5916.

Fu NY, Yuan YF, Cao Z, Wang SW, Wang JT and Peppe C (2002), Indium(III) Bromide-Catalyzed Preparation of Dihydropyrimidinones: Improved Protocol Conditions for the Biginelli Reaction, Tetrahedron 58: 4801-4807.

Ghomi JS, Teymuri R and Ziarati A (2013), A green synthesis of 3,4-dihydropyrimidine-2(1H)-one/thione derivatives using nanosilica-supported tin(II) chloride as a heterogeneous nanocatalyst, Monatsh Chem 144: 1865-1870. DOI: 10.1007/s00706-013-1068-6

Jaberi ZK and Moaddeli MS (2012), Synthesis of 3,4-dihydropyrimidin-2(1H)-ones and their corresponding $2(1 \mathrm{H})$ thiones using trichloroacetic acid as a catalyst under solvent-free conditions, ISRN Org. Chem., 4 pages.

Kappe CO (1993), 100 years of the Biginelli dihydropyrimidine synthesis, Tetrahedron 49: 6937-6963.

Kappe CO (2000), Recent advances in the Biginelli dihydropyrimidine synthesis. New tricks from an old dog, Acc. Chem. Res. 33: 879-888.

Kong R, Han SB, Wei JY, Peng XC, Xie ZB, Gong SS and Sun Q (2019), Highly efficient synthesis of substituted 3,4-dihydropyrimidin-2-(1H)-ones (DHPMs) catalyzed by $\mathrm{Hf}(\mathrm{OTf}) 4$ : Mechanistic insights into reaction pathways under metal Lewis acid catalysis and solvent-free conditions, Molecules 24: 364-377.

Laville R, Thomas OP, Berrué F, Marquez D, Vacelet J and Amade P (2009), Bioactive guanidine alkaloids from two caribbean marine sponges, J. Nat. Prod. 72: 1589-1594.

Lu J, Bai Y, Wang Z, Yang B and Ma H (2000), One-pot synthesis of 3,4-dihydropyrimidin-2(1H)-ones using lanthanum chloride as a catalyst, Tetrahedron Lett. 41: 9075-9078.

Lu J and Ma H (2000), Iron (III)-catalyzed synthesis of dihydropyrimidinones. Improvedconditions for the Biginelli reaction, Synlett 2000: 63-64. DOI: $10.1055 / \mathrm{s}-2000-6469$

Maiti G, Kundu P and Guin C (2003), One-pot synthesis of dihydropyrimidinones catalysed by lithium bromide: an improved procedure for the Biginelli reaction,Tetrahedron Lett. 44: 2757-2758. DOI: org /10.1016/S0040-4039(02)02859-9

Mandhane PG, Joshi RS, Nagargoje DR and Gill CH (2010), An efficient synthesis of 3,4-dihydropyrimidin-2 (1H)-ones catalyzed by thiamine hydrochloride in water under ultrasound irradiation, Tetrahedron Lett. 51: 3138-3140. DOI: org/10.1016/j.tetlet.2010.04.037

Maskrey TS, Frischling MC, Rice ML and Wipf P (2018), A five-component Biginelli-Diels-Alder cascade 
reaction, Front. Chem. 6: 376 . DOI: 10.3389/fchem.2018.00376

Mirzaei YR, Azamat H and Namazi H (2001), Investigation the reactivity of Ppositions N-3, C-5 and C6-methyl group in Biginelli type compounds and synthesis of new dihydropyrimidine derivatives, J. Heterocycl. Chem. 38: 1051-1054. DOI: org/10.1002/jhet.5570380507

Pasunooti KK, Chai H, Jensen CN, Gorityala BK, Wang S and Liu XW (2011), A microwave-assisted, copper catalyzed three-component synthesis of dihydropyrimidinones under mild conditions, Tetrahedron Lett. 52: 80-84. DOI: org/10.1016/j.tetlet.2010.10.150

Patil AD, Kumar NV, Kokke WC, Bean MF, Freyer AJ, De Brosse C, Mai S, Truneh A, Faulkner DJ, Carte B, Breen AL, Hertzberg RP, Johnson RK, Westley JW and Potts BCM (1995), Novel Alkaloids from the Sponge Batzella sp.: Inhibitors of HIV gp120-Human CD4 Binding, J. Org. Chem. 6: 1182-1188. DOI: org/ 10.1021/jo00110a021

Patil S, Jodhav SD and Deshmukh MB (2011), Natural acid catalyzed multi-component reactions as a green approach, Arch. Appl. Sci. Res. 3: 203-208.

Paraskar AS, Dewkar GK and Sudalai A (2003), Cu(OTf)2: a reusable catalyst for high-yield synthesis of 3,4-dihydropyrimidin-2(1H)-ones, Tetrahedron Lett. 44: 3305-3308. DOI: org/10. 1016/S0040-4039 (03)00619-1

Rajeshwari M, Priyanka K and Sarada LN (2013), Chloromine-T: A simple and efficient catalyst for one-pot synthesis of Biginelly 3,4dihydropyrimidin-2-(1H)-ones, Indian J. Adv. Chem. Sci. 1: 112-116.

Ranu BC, Hajra A and Jana U (2000), Indium(III) chloride-catalyzed one-pot synthesis of dihydropyrimidinones by a three-component coupling of 1,3-dicarbonyl compounds, aldehydes, and urea: aan improved procedure for the Biginelli reaction, J. Org. Chem. 65: 6270-6272. DOI: org/ 10.1021/ jo000711f

Reddy V, Mahesh M, Raju PVK, Babu TR and Reddy VVN (2002), Zirconium(IV) chloride catalyzed one-pot synthesis of 3,4-dihydropyrimidin-2(1H)-ones, Tetrahedron Lett. 43: 2657-2659. DOI: org/ 10.1016/ S0040- 4039(02)00280-0
Rovnyak GC, Kimball SD, Beyer B, Cucinotta G, DiMarco JD, Gougoutas J, Hedberg A, Malley M, McCarthy JP, Zhang R and Moreland SJ (1995), Calcium Entry Blockers and Activators: Conformational and Structural Determinants of Dihydro-Pyrimidine Calcium Channel Modulators, J. Med. Chem. 38: 119-129. DOI: org/10.1021/ jm00001a017

Sabitha G, Reddy KB, Yadav JS, Shailaja D and Sivudu KS (2005), Ceria/vinyl pyridine polymer nanocomposite: an ecofriendly catalyst for the synthesis of 3,4-dihydropyrimidin-2(1H)-ones, Tetrahedron Lett. 46: 8221-8222. DOI: org/ 10.1016/j.tetlet. 2005.09.100

Sadek KU, Al-Qalaf F, Khalik MMA and Elnagdi MH (2010), Cerium (IV) ammonium nitrate as an efficient Lewis acid for one-pot synthesis of 3,4-dihydropyrimidin $-2(1 \mathrm{H})$-ones and their corresponding 2(1H)-thiones, J. Heterocycl. Chem. 47: 284-286. DOI: org/ 10.1002/jhet.259

Salim SD and Akamanchi KG (2011), Sulfated tungstate: an alternative, eco-friendly catalyst for Biginelli reaction, Catal. Commun. 12: 1153-1156. DOI: org/ 10.1016/ j.catcom.2011.02.018

Shaaban MR, Saleh TS, Mayhoub AS, Mansour A and Farag AM (2008), Synthesis and analgesic/anti-inflammatory evaluation of fused heterocyclic ring systems incorporating phenylsulfonyl moiety, Bioorg. Med. Chem. 16: 6344-6352. DOI: org/10.1016/ j.bmc.2008.05.011

Snider BB and Shi Z (1993), Biomimetic synthesis of (.+-.) crambines A, B, C1 and C2. Revision of the structure of crambines B and C1, J. Org. Chem. 58: 3828-3839. DOI: org/10.1021/jo00067a014

Shapiro N and Vigalok A (2008), Highly efficient organic reactions 'on water' and 'in water' and both, Angewandte Chemie 120: 2891-2894. DOI: org/10.1002/ange.200705347

Shen ZL, Xu XP and Ji SJ (2010), Bronsted base-catalyzed one-pot three component Biginelli type reaction: an efficient synthesis of 4,5,6-triaryl-3, 4-dihydropyrimidin-2(1H)-one and mechanistic study, J. Org. Chem. 75: 1162-1167. DOI: org/ 10.1021/jo902394y

Salehi P, Dabiri M, Zolfigol MA and Bodaghi Fard MA (2003), Silica sulfuric acid: an efficient and reusable catalyst for the one-pot synthesis of 
3,4-dihydropyrimidin- 2(1H)-ones, Tetrahedron Lett. 44: 2889-2891. DOI: org/10.1016/S0040- 4039(03) $00436-2$

Sabitha G, Reddy GSKK, Reddy KB and Yadav JS (2003), Vanadium(III) chloride catalyzed Biginelli condensation: solution phase library generation of dihydropyrimidin- $(2 \mathrm{H})$-ones, Tetrahedron Lett. 44: 6497-6499. DOI: org/10.1016/S0040 -4039(03) 01564-8

Sun Q, Wang Y, Ge Z, Cheng T and Li R (2004), A highly efficient solvent-free synthesis of dihydropyrimidinones catalyzed by zinc chloride, Synthesis 7: 1047-1051 and references therein. DOI: $10.1055 / \mathrm{s}-2004-822331$

Snider BB, Chen J and Patil AD and Freyer A (1996), Synthesis of the tricyclic portions of batzelladines A, B and D. Revision of the stereochemistry of batzelladines A and D, Tetrahedron Lett. 37: 6977-80. DOI: 10.1016/0040-4039(96)01575-4

Tamaddon F, Razmi Z and Jafari AA (2010), Synthesis of 3, 4-dihydropyrimidin-2(1H)-ones and 1,4-dihydropyridines using ammonium carbonate in water, Tetrahedron Lett. 51: g1187-1189. DOI: org/10.1016/j.tetlet.2009.12.098

Tu S, Fang F, Miao C, Jiang H, Feng Y, Shi D and Wang X (2003), One-pot synthesis of 3,4-dihydropyrimidin-2
(1H)-ones using boric acid as catalyst, Tetrahedron Lett. 44: 6153-6155. DOI: org/ 10.1016/ S0040-4039 (03)01466-7

Tsuruo T, Iida H, Nojiri M, Tsukagoshi S and Sakurai Y (1983), Circumvention of vincristine and adriamycin resistance in vitro and in vivo by calcium blockers, Cancer Res. 43: 2905-2910.

Van Zandt MC, Jones ML, Gunn DE, Geraci LS, Jones JH, Sawicki DR, Sredy J, Jacot JL, Di-Cioccio AT, Petrova T, Mitschler A and Podjarny AD (2005), Discovery of 3-[(4,5,7- triflurobenzothiazol2-yl)methyl] indole-N-acetic acid (lidorestat) and congeners as highly potent and selective inhibitors of aldose reeducates for treatment of chronic diabetic complications, J. Med. Chem. 48: 3141-3152. DOI: org/ $10.1021 / \mathrm{jm} 0492094$

$\mathrm{Xu} \mathrm{H}$ and Wang YG (2003), A rapid and efficient Biginelli reaction catalyzed by zinc triflate, Chin. J. Chem. 21: 327-331. DOI: org/10.1002/cjoc.20030210321

Yadav JS, Reddy BVS, Reddy KB, Raj KS and Prasad AR (2001), Ultrasound-accelerated synthesis of 3,4-dihydropyrimidin-2(1H)-ones with ceric ammonium nitrate, J. Chem. Soc. Perkin Trans. 1: 1939-1941. 